\title{
O império na ponta da pena: cartas e regimentos dos governadores-gerais do Brasil
}

\author{
Marilia Nogueira dos Santos**
}

"Senhor. É do Regimento deste Estado dar conta
a Vossa Magestade por carta.
E em cumprimento delle me é preciso dizer
a Vossa Magestade como achei este Governo
quando cheguei a elle, e do estado em que fica".***

O presente artigo busca entender como o modo de governar a América portuguesa, pouco a pouco, foi tendo suas bases assentadas na escrita. Para tal, faz uso dos regimentos dados aos governadores-gerais, desde 1548, ano da instalação do governo-geral na Bahia, para, posteriormente, compará-los à correspondência do governador-geral

\footnotetext{
* Artigo recebido e aprovado para publicação em junho de 2009. Este artigo faz parte da minha dissertação de mestrado, defendida em março de 2007, no Programa de Pós-Graduação da Universidade Federal Fluminense, sob a orientação de Maria de Fátima Silva Gouvêa. Trabalhei com Fátima desde o segundo período da graduação (2001). Fui sua bolsista de Iniciação Científica e foi ela quem me apresentou ao mundo do Antigo Regime português. Foi ela quem me fez sonhar com e viajar por esse mundo. Foi ela quem me contagiou com o seu amor pela História e pela profissão de historiador. A ela eu devo todo o pouco que sei.

** Doutoranda do Programa de Pós-Graduação em História Social da Universidade Federal do Rio de Janeiro - PPGHIS/UFRJ e bolsista do CNPq. E-mail: marilia.niti@gmail.com

*** "Carta geral que foi a Sua Magestade sobre diversos particulares" (25/06/1691), in: "Cartas que o Senhor Antonio Luiz Gonçalves da Câmara Coutinho Governador da Capitania deste Estado do Brasil escreveu a Sua Magestade pela Secretaria de Estado nesta frota de que é Capitão de mar, e Guerra Lourenço Nunes, que parte hoje 17 de Julho de 1691” publicado nos Documentos Históricos da Biblioteca Nacional, volume 33 - Provisões, Patentes, Alvarás, Cartas (1648-1711), Rio de Janeiro, Typ.Arch. de Hist. Bras., 1936, p. 356.
} 
Antônio Luís Gonçalves da Câmara Coutinho. Desse modo, pretende-se demonstrar como carta e regimento eram conjugados tendo em vista o bom governo do Estado do Brasil.

Palavras-chave: Cartas - Regimentos - Governadores-Gerais

The empire on the tip of the pen: letters and instructions of the general governors in Brazil

The present article seeks to understand how the way of ruling the Portuguese America gradually started to be put to writing. For that purpose, the author takes the titles of privilege granted to the general governors since 1548, the year of installation of the general government in Bahia, and compares them with the correspondence of the general governor Antônio Luís Gonçalves da Câmara Coutinho. The article intends to demonstrate how the letters and the titles were combined in order to ensure a good government to the State of Brazil.

Keywords: Letters - Instructions - General Governors

L'empire à la pointe de la plume: Chartes et ordonnances des gouverneurs généraux du Brésil

Le présent article cherche à comprendre comment la façon de gouverner l'Amérique portugaise a commencé peu a peu à se fonder sur l'écriture. Pour ce faire, l'auteur se base sur les regimentos (Titres de privilèges) octroyés aux gouverneurs généraux depuis 1548, année de l'installation du gouvernement général à Bahia, pour ensuite les comparer à la correspondance du gouverneur général Antônio Luís Gonçalves da Câmara Coutinho. L'article tente, de cette façon démontrer comment les chartes et les titres de privilèges étaient conjugués en vue d'assurer un bon gouvernement à l'Etat du Brésil.

Mots-clés: Chartes - Ordonnances - Gouverneurs Généraux

Parte da "Carta geral que foi a Sua Magestade sobre diversos particulares", escrita em Salvador por Antônio Luís Gonçalves da Câmara Coutinho, em 25 de junho de 1691, a epígrafe que abre esse artigo faz menção a dois assuntos fundamentais para o entendimento da administração ultramarina portuguesa, porém pouco estudados: as cartas e os regimentos dos governadores-gerais do Estado do Brasil. Serão esses, portanto, os assuntos principais da reflexão que se inicia. Serão então analisados os regimentos dados aos governadores-gerais do Brasil, desde 1548, para, posteriormente, passar-se à problematização geral 
da correspondência desses mesmos ministros. Nesse sentido, eleger-se-á como estudo de caso a correspondência de Câmara Coutinho.

\section{$* * *$}

No período em que Portugal esteve sob domínio filipino, muitas mudanças foram introduzidas no modo de ser da administração reinol. Em se tratando do governo-geral instalado em Salvador, em 1548, o período em questão foi bastante produtivo. Quarenta anos depois do primeiro regimento para o governo-geral, já no reinado de Filipe II, um outro documento foi elaborado, sendo seguido posteriormente por mais dois, um em 1612 e outro em 1624. Com a restauração já concluída, D. Pedro II entregava novo regimento a Roque da Costa Barreto, mas isso é assunto para mais adiante.

Comparar os regimentos produzidos antes, durante e depois da união das coroas se mostra bastante relevante para o entendimento da principal questão deste artigo, isto é, a escrita de cartas por parte dos governadoresgerais. Francisco Cosentino, em tese de doutorado defendida, apresenta um árduo trabalho de pesquisa visando à comparação dos cinco regimentos que ele denominou ordenadores do governo-geral do Brasil. ${ }^{1}$ Sem desmerecer nem um pouco o bom trabalho desenvolvido por Cosentino, importa agora comparar os quatro primeiros regimentos, priorizando a análise da introdução de um modo de governar baseado na escrita, característico do período filipino.

Filho de João de Sousa e Mércia Rodrigues de Faria, após passagens pela África e Ásia, Tomé de Sousa foi incumbido da importante missão de instituir o governo-geral na Bahia. ${ }^{2}$ Saído de Lisboa em $1^{\circ}$ de fevereiro de 1549 , cerca de um mês depois, em 28 de março, aportou na cidade de Salvador, de posse do primeiro regimento para o governo-geral do Brasil. ${ }^{3}$

Segundo Francisco Cosentino, o regimento trazido por Sousa, escrito em Lisboa em 1548, ainda no reinado de D. João III, representava o começo da construção de uma administração mais normatizada nas então ainda partes do Brasil. A opção de denominar os domínios portugueses na América de

\footnotetext{
${ }^{1}$ Francisco Carlos Cardoso Cosentino, Governadores Gerais do Estado do Brasil (séculos XVI e XVII): ofício, regimentos, governação e trajetórias, Niterói, Universidade Federal Fluminense, 2005. Tese de Doutorado.

${ }^{2}$ Para maiores detalhes da trajetória de Tomé de Sousa, ver o $12^{\circ}$ capítulo da tese de doutorado de Francisco Cosentino, citada na nota anterior.

${ }^{3}$ Ignácio Accioli, Memórias históricas e políticas da província da Bahia, Salvador, Imprensa Oficial do Estado, 1919, vol. 1, p. 245-246.
} 
partes e não de Estado, nos dois primeiros regimentos, refletia o processo de construção de uma unidade política, ainda em fase inicial. ${ }^{4}$

Assim, no regimento dado a Tomé de Sousa, composto por 46 capítulos, o assunto que mais merece destaque é a defesa, uma vez que nesse momento uma forma de governo estava começando a ser desenhada. E parece ser possível afirmar que nessa forma o uso da escrita como instrumento de governação não era ainda valorizado, pois, se a preocupação com a defesa era grande, o mesmo não se pode dizer sobre se informar o rei do que acontecia em terras americanas. Se cerca de um terço dos 46 capítulos do regimento referiam-se à defesa, em somente dois deles encontra-se orientação sobre se escrever ao rei. Vejamos: já na parte final, ao instruir o governador-geral sobre a construção de navios a remo para a defesa contra os corsários, diz o rei que

vós com o dito Provedor-mor de minha fazenda e com os Capitães, Provedores e Oficiais das tais Capitanias, e com as mais pessoas que vos parecer que o bem entendem, praticareis a maneira que se terá de fazerem os ditos navios de remo (...); e do que assentardes, farei auto que me enviareis para, com vossa informação, prover nisso como houver por meu serviço. ${ }^{5}$

O segundo capítulo em questão se trata do último capítulo do regimento, aquele que o encerra e orienta o governador sobre como agir caso ocorresse alguma situação que não estivesse prevista no dito documento. Nesse caso, deveria Tomé de Sousa reunir-se com outros oficiais do rei e "quaisquer outras pessoas que virdes q nelas vos poderão dar informação e conselho" para chegar a uma solução. Caso as opiniões, os "pareceres" nas palavras do rei, fossem diferentes uns dos outros, deveria o governador fazer o que ele tivesse decidido e "(...) de tais cousas se fará assento, em que se declarará as pessoas com as práticas e o parecer delas e o vosso, para mo escreverdes, com as primeiras cartas que, após isso, me enviardes". ${ }^{6}$

Se, por um lado, se fica com a impressão, a partir desses dois trechos, de que a prática de se mandar notícias do ultramar via cartas não era muito corrente na monarquia portuguesa, por outro, deve-se levar em conta o fato de ser esse o primeiro regimento produzido com o intuito de regular e insta-

\footnotetext{
${ }^{4}$ Francisco Carlos Cardoso Cosentino, op. cit., p. 117.

${ }^{5}$ Regimento de Tomé de Sousa, escrito em Almerim, aos 17 de dezembro de 1548, publicado em: Marcos Carneiro de Mendonça, Raízes da formação administrativa do Brasil, Rio de Janeiro, Instituto Histórico e Geográfico Brasileiro/Conselho Federal de Cultura, 1972, p. 49. Grifo meu.
}

${ }^{6}$ Idem, p. 51. Grifo meu. 
lar o governo-geral na América portuguesa. Reflete, portanto, as principais preocupações em relação às partes do Brasil que, à época, assolavam D. João III, isto é, a manutenção e defesa de seus domínios no Atlântico sul. ${ }^{7}$ No entanto, deve-se levar em consideração que esse regimento não caiu em desuso com o fim do governo de Tomé de Sousa no Brasil, em $1553 .{ }^{8}$ Fizeram uso dele ainda mais cinco governadores. Dois deles, Lourenço da Veiga e Manuel Telles Barreto, governaram já sob influência de Filipe II. E é nesse momento que as coisas começam a mudar.

Em 1588, Francisco Giraldes era escolhido o novo governador-geral do Brasil. No entanto, "depois de uma viagem atribulada", não conseguiu desembarcar na Bahia, tendo de retornar a Portugal. Trazia Giraldes o segundo regimento para o governo-geral do Brasil, cuja preservação foi possível. É por isso mesmo considerado o primeiro regimento do período filipino.

Apesar de não ter sido posto em prática por Francisco Giraldes, o regimento produzido por ocasião de sua escolha regeu os governos de três governadores-gerais. Se contrastado com o primeiro regimento trazido por Tomé de Sousa, o de Francisco Giraldes não apresenta grandes mudanças em termos dos assuntos abordados. Tal qual no de Tomé de Sousa, o termo Estado ainda não se faz presente. Quem teve suas atividades regidas por ele governou as partes do Brasil e não o Estado do Brasil. ${ }^{10}$ Se no geral os assuntos tratados são muito próximos, não sendo incomum a menção ao regimento de Tomé de Sousa, começam a surgir no de Francisco Giraldes mudanças significativas na forma de ser da governação das partes do Brasil. Se dos 46 capítulos do primeiro regimento somente dois faziam referência à necessidade de se informar ao rei, no de Giraldes, composto por 53 capítulos, esse número avança para sete.

Pela primeira vez é feita menção à maneira como o governador deveria tomar posse do seu cargo, ${ }^{11}$ instrução que já apontava uma preocupação com 7 Para uma contextualização da época em que esse regimento foi produzido, ver: Francisco
Carlos Cardoso Cosentino, op. cit., p. 114-120.
${ }^{8}$ Para uma caracterização do governo de Tomé de Sousa, ver: Francisco Adolfo de Varnha-
gen, História Geral do Brasil, 5 tomos, 9 a edição, São Paulo, Melhoramentos, 1975, Tomo 1;
Pedro Calmon, História do Brasil, 7 volumes, Rio de Janeiro, José Olímpio, 1959; Ignácio
Accioli, op. cit., vol. 1 e Francisco Carlos Cardoso Cosentino, op. cit., p. 204-214.
${ }^{9}$ Idem, p. 272.
${ }^{10}$ Idem, p. 120.
${ }^{11}$ Sobre o ritual de posse dos governadores-gerais do Brasil, ver o $4{ }^{\circ}$ capítulo da tese de dou-
torado de Francisco Cosentino, indicada nas notas anteriores. 
o registro da informação, típica do reinado de Filipe II. Mas as diferenças não param por aí. Mesmo quando o assunto remonta ao regimento de Tomé de Sousa, ainda assim, percebe-se um significativo salto na forma de ser da governação que então se intentava implementar.

Identificada por D. João III como a "principal cousa" que o "moveu a mandar povoar as ditas terra do Brasil", a conversão dos índios à fé católica merece destaque no primeiro regimento. Deveria ele, junto com os capitães e oficiais, encontrar a melhor maneira para que isso pudesse ser feito e, neste caso, dizia o rei que agradeceria muito "terem especial cuidado de os provocar a serem Cristãos". Continuava dizendo que "para êles mais folgarem de o ser" deveria Tomé de Sousa cuidar para que todos os índios que fossem "de paz" recebessem bom tratamento, instruindo, inclusive, o favorecimento dos mesmos. Além disso, não deveria ser feita nem opressão nem agravo contra os indígenas e, caso isso ocorresse, encomendava ao governador que "lho façam corrigir e emendar, de maneira que fiquem satisfeitos, e as pessoas que lhos fizerem, sejam castigados como fôr justiça". ${ }^{12}$

Capítulo semelhante, quase igual - não fosse uma diferença significativa - pode ser encontrado no regimento de Francisco Giraldes. Fazendo referência ao expresso desejo motivador de D. João III, mencionado acima, chama a atenção para o fato de ser

obrigação mui devida a esta Coroa, a quem Deus encomendou tão grandes conquistas, para Eu, sucedendo nela a cumprir, como desejo, vos encomendo muito que disto tenhais mui particular cuidado, como convém, para eu descançar no que fizerdes em tão grande matéria, de que me avisareis sempre.... $)^{13}$

Pode-se perceber como, não obstante a preocupação com a conversão dos índios ser compartilhada pelos dois reis, diferente de D. João III, Filipe II fazia questão de ser avisado sempre acerca do que fosse feito a esse respeito.

Com a morte de Filipe II, seu filho e herdeiro Filipe III assumiu os tronos ora ocupados por seu pai. Nesse contexto, Gaspar de Sousa, $10^{\circ}$ governador-geral do Brasil, desembarcou em Salvador em dezembro de 1613 e, assim como Tomé de Sousa e Francisco Giraldes (caso esse tivesse de fato pisado em terras americanas), também chegara de posse de um novo regimento para o governo-geral do Brasil.

\footnotetext{
${ }^{12}$ Regimento de Tomé de Sousa, op. cit., p. 43.

${ }^{13}$ Regimento de Francisco Giraldes, op. cit., p. 260. Grifo meu.
} 
Escrito em Lisboa aos seis dias de outubro de 1612, o terceiro regimento para o governo-geral do Brasil era o segundo do período filipino e o primeiro do tempo de Filipe III como rei de Portugal. Composto por 59 capítulos, é o primeiro em que aparece a palavra Estado para qualificar as partes portuguesas da América, sinal do crescente enraizamento de um modo de governar que encontrava eco na maior complexificação e unidade do aparelho administrativo construído no agora Estado do Brasil. ${ }^{14}$ Modo de governar cada vez mais assentado na prática da escrita, no registro e na circulação da informação, não só entre a América e a Europa mas, também, no interior da própria América. E disso o regimento de Gaspar de Sousa é exemplar.

Se no regimento de Francisco Giraldes sete dos 53 capítulos faziam referência ao envio de informação por parte do governador ao rei, quando se analisa o de Gaspar de Sousa constata-se que, dos 59 capítulos, 22 fazem esse tipo de referência; ou seja, constata-se um grande aumento no número de assuntos sobre os quais o rei queria ser informado. No início do século XVII o rei continuava querendo ser informado sobre a conversão dos índios, mas também sobre o governo do Rio Grande, atual Rio Grande do Norte, sobre a conservação da artilharia, sobre o ordenado dos bispos, entre outros. Mas, além de querer ser informado sobre os assuntos específicos tratados ao longo dos capítulos, Filipe III inova no capítulo 58 ao instruir Gaspar de Sousa que

sejais mui contínuo em me escrever e avisar de todas as cousas que sucederem, e de que entenderdes convém ser avisado, assim do que a experiência vos mostrar ser necessário para bom governo dele, como do procedimento das pessoas que nêle me servem, o que fareis com todos os navios que partires das partes e lugares onde vos achardes sem vir nenhum sem carta vossa, inda que seja repetido o já escrito; porque assim convém pela incerteza da viagem do mar. ${ }^{15}$

Como se pode facilmente constatar, cada vez mais o governador-geral do Brasil estava instruído a mandar notícias e informações do outro lado do Atlântico, agora num sentido mais lato: deveria informar sobre todos os assuntos especificados nos já citados 22 capítulos e sobre tudo o mais que a experiência mostrasse ser importante e necessário informar ao rei. Deveria ainda

\footnotetext{
${ }^{14}$ Francisco Carlos Cardoso Cosentino, op. cit., p. 100-101.

${ }^{15}$ Regimento de Gaspar de Sousa, escrito em Lisboa a 6 de outubro de 1612, publicado em Marcos Carneiro de Mendonça, Raíses da formação administrativa do Brasil, Rio de Janeiro, Instituto Histórico e Geográfico Brasileiro/Conselho Federal de Cultura, 1972, p. 436.
} 
ter particular cuidado de saber de todos os navios que desta cidade partirem, se levam despachos meus para vós, e que vô-los entregue, ou certidão do Secretário das matérias do estado do dito Conselho [da Índia]. ${ }^{16}$

Repare-se como a partir desses dois capítulos é possível perceber como o regimento de Gaspar de Sousa reafirma e reforça a prática de se governar por escrito. Além de instruir sobre o envio de informação ao reino, passava também a instruir sobre a forma de se enviar essas informações.

Em termos da consolidação de um modo de governar assentado na escrita, pode-se dizer que a preocupação em regular a forma de envio de informação é a principal diferença encontrada no regimento de Diogo Mendonça Furtado, em relação aos anteriores. O texto do capítulo sobre ser o governador obrigado a escrever ao rei foi mantido praticamente na íntegra, tendo apenas algumas palavras modificadas. No entanto, a forma de enviar o que fosse escrito passava a receber atenção especial. Dizia o documento:

Das materias de Estado de que me houverdes de dar conta tocantes a vossa obrigação me avizareis por via dos meos Secretários de Estado, que assistem nessa Cidade em a Corte e na Corte de Madrid, das Fazenda por via do meo Conselho della das da Índia pelo do Desembargo do Paço e dos Ecleziasticos pela meza da Consciência e Ordens e assim o cumprireis inteiramente tendo particular cuidado de dividir os negócios de maneira que não venhão de lá encaminhados de diferente modo de que neste Capitulo se vos avisa. ${ }^{17}$

Continuava também o governador obrigado a ir ao encontro dos mestres dos navios em busca de notícias e novas ordens vindas da corte, sendo, inclusive, orientado a demonstrar o quão grave era a chegada de um navio sem notícia alguma.

Datado de 16 de janeiro 1621, o regimento de Mendonça Furtado foi o que mais tempo ficou em vigor, entre os do período dos Filipes: regeu as atividades dos governadores-gerais do Brasil de 1621 até 1677, ou seja, durou mais de meio século, sobrevivendo, inclusive, à união das coroas. Sessenta anos depois de Filipe II ter vencido a disputa pelo trono luso, em $1^{\circ}$ de dezembro de 1640, Portugal voltava a ser governado por um rei português. Começava nesse momento o tempo dos Bragança no poder. No entanto, segundo Reis Torgal, é possível verificar que D. João IV manteve em pleno exercício os órgãos

${ }^{16}$ Idem, p. 435.

${ }^{17}$ Regimento dado a Diogo de Mendonça Furtado - APEB, S.C., estante 1, caixa 146, livro 264, p. 114, apud Francisco Carlos Cardoso Cosentino, op. cit., p. 139-140. 
existentes durante o tempo dos Filipes, confirmou as mercês concedidas no período, bem como as Ordenações Filipinas continuaram em vigor, mesmo após 1640. Pouco a pouco, a nova dinastia foi se reorganizando, reestruturando o Estado Moderno português, através da criação de novos órgãos administrativos, embora utilizando por vezes os já existentes ou concebidos ao longo da união das coroas. Parece claro que as mais significativas mudanças diziam respeito ao modo de governar não só o reino, mas também e, principalmente, o ultramar; isto é, governar por escrito deixava de ser exceção para se tornar cada vez mais a regra, vide a manutenção do sistema de secretarias. ${ }^{18} \mathrm{O}$ que não é de se estranhar caso se tenha em conta que o período compreendido entre a instalação do governo-geral e o início da união das coroas foi muito curto, apenas 32 anos, se comparado ao tempo em que o mesmo governo esteve sob domínio filipino, que durou 60 anos; ou seja, apesar da instalação do governo-geral ter sido obra dos portugueses, coube aos espanhóis o seu desenvolvimento e aprimoramento. Coube aos espanhóis a implementação de um modo de governar, de gerir o vasto território da América portuguesa, que cresceu ainda mais durante o período. Só para o governo-geral foram

${ }^{18}$ Apesar de já existir nas principais cortes europeias a figura do secretário, em se tratando de Portugal, a denominação "secretário de Estado" remonta ao período filipino. Em 1602, ao tempo do reinado de Filipe III de Espanha, II de Portugal, existiam quatro secretários, cada um atrelado a uma área do governo central. Para fazer a ligação entre o rei, o Desembargo do Paço e o Conselho de Estado, existia o secretário dos negócios de Estado e justiça. A ligação com a Mesa de Consciência e Ordens ficava a cargo do secretário das matérias de consciência e ordens. Já o secretário da fazenda fazia a ligação com o conselho de mesmo nome, e, por fim, existia ainda o secretário do despacho das petições e mercês. No entanto, essa organização não durou muito tempo. Cinco anos depois, em 1607, as secretarias foram reduzidas a duas, a partir do acúmulo de funções; ou seja, o secretário de negócios de Estado e justiça passou a tratar também das questões de consciência e ordens e o da fazenda, por sua vez, agregou às suas responsabilidades o despacho das mercês. Essa situação perdurou até 1631, quando às duas secretarias já existentes foi adicionada outra, dedicada aos negócios das Índias e das conquistas. Para além dessas três secretarias, existiram em Portugal durante a monarquia dual mais dois secretários fixos: o secretário de Estado e o secretário das mercês. Imediatamente ao fim da união dinástica, o número de secretarias em Portugal foi reduzido a uma, somente, que recebeu o nome de secretaria de Estado. No entanto, já em 1643, D. João IV criou, por alvará de 29 de novembro de 1643, a Secretaria das Mercês e Expediente, sendo Gaspar de Farias Severim o primeiro a ocupar o cargo de secretário das mercês e expediente. Essa estrutura permaneceu até finais dos seiscentos, quando foi criada outra Secretaria, qual seja, a Secretaria das Assinaturas. Esta última ficava encarregada do processamento da parte final de todos os documentos aos quais o rei deveria assinar. Sendo assim, ao final do século XVII, existiam em Portugal três secretarias, o que, em 1736, foi reformado pelo rei D. João V. Após a morte de Diogo de Mendonça Corte Real, então secretário de Estado, foram criadas três Secretarias de Estado: a Secretaria de Estado do Reino, a Secretaria de Estado dos Negócios Estrangeiros e de Guerra, e, por fim, a Secretaria de Estado da Marinha e do Ultramar. 
quatro os regimentos, contando o de Manuel Telles Barreto que, como visto, desapareceu. Esse número aumenta se acrescentados, pelo menos, mais 10 regimentos relativos aos outros órgãos, tais como a Provedoria da Fazenda (1592), o Conselho da Índia (1604), a Casa de Suplicação (1605), a Relação da Bahia (1609). ${ }^{19}$

É por tudo isso que Francisco Cosentino aponta este momento como aquele em que os poderes régios delegados aos governadores aumentaram. As regalias, ou seja, poderes exclusivamente do rei delegados ao exercício de outra pessoa, no caso os governadores-gerais, foram sendo progressivamente alargadas. A conclusão de Cosentino vai de encontro às análises mais antigas, segundo as quais a implementação do governo-geral do Brasil era sinônimo de uma centralização em curso na Europa. Ao contrário, Cosentino aponta o período como o de ampliação do protagonismo régio, da centralidade do rei. Mas, paralelamente a esse movimento, aumentava também a importância, o protagonismo do governador-geral na América portuguesa. O governador passava, cada vez mais, a ser o representante do rei em terras tão longínquas. ${ }^{20}$

No entanto, não se pode esquecer que, se por um lado, os poderes dos governadores-gerais foram, progressivamente, alargados, por outro, esses mesmos governadores estavam cada vez mais obrigados a informar aos reis os seus atos. É bem verdade que os governadores podiam fazer determinadas mercês, mas estas não valeriam se não houvesse a confirmação do rei. Como bem percebeu o historiador britânico John Elliott:

Os funcionários da coroa nas Índias, dispondo teoricamente de plena liberdade nos grandes espaços abertos de um grande Novo Mundo, viram-se acorrentados por cadeias de papel ao governo central da Espanha. Pena, tinta e papel eram os instrumentos com que a coroa espanhola respondia aos inéditos desafios da distância implícitos na posse de um império de amplitude mundial. ${ }^{21}$

Ainda segundo Elliot, corroborando o argumento de Bouza Álvarez, pouco a pouco, também no ultramar, o governo, por meio da palavra oral, foi

\footnotetext{
19 Todos esses regimentos estão publicados em Marcos Carneiro de Mendonça, Raízes da formação administrativa do Brasil, Rio de Janeiro, Instituto Histórico e Geográfico Brasileiro/Conselho Federal de Cultura, 1972.

${ }^{20}$ Francisco Carlos Cardoso Cosentino, op. cit., p. 106-114.

${ }^{21}$ J. H. Elliott, "A Espanha e a América nos séculos XVI e XVII”, in: BETHEL, Leslie (org.), História da América Latina: América Latina Colonial, vol. 1, São Paulo, EDUSP, 1997, p. 287.
} 
sendo substituído pelo governo através da escrita. ${ }^{22}$ Com os Filipes, a América portuguesa passou progressivamente a ser governada tendo como principais instrumentos a pena, a tinta e o papel. É bem verdade que esta mudança longe está de ser um sinal de centralização, mas também não se pode negar que a escrita passou a ser muito bem utilizada como forma de dominar um império tão vasto. Somente com o recurso à escrita foi possível a manutenção desse império - império esse que não era, "muitas vezes, mais do que um 'império de papel', em que a correspondência do rei, dos vice-reis, dos governadores, dos capitães, substituíam laços políticos mais efectivos". ${ }^{23}$ Nesse sentido, o estudo das cartas produzidas e/ou destinadas aos governadores-gerais ganha cada vez mais importância.

No entanto, não se pode esquecer que, após a Restauração, outro regimento foi elaborado. Analisá-lo à luz dos produzidos no período filipino torna-se deveras importante.

Segundo Maria de Fátima Gouvêa, os anos de 1670 são exemplares da maior atenção dada pelo regente D. Pedro aos seus domínios ultramarinos. Em se tratando da parte africana do Atlântico, viu-se a fundação de novos presídios em Angola. A fundação de Pungandongo, em 1671, e Caconda, em 1682, viabilizaram o estabelecimento de novas rotas de tráfico de escravos. Já na parte americana do Atlântico sul, o que se viu, segundo Gouvêa, foi o início de um reordenamento da forma de ser da administração. Em 1675 e 1676, foram criados os bispados de Olinda e do Rio de Janeiro, respectivamente. Já o da Bahia foi elevado a arcebispado. Nesse mesmo período, capitanias na parte sul da América portuguesa foram outorgadas mais sistematicamente, culminando com a fundação da Nova Colônia de Sacramento, em $1680 .{ }^{24}$ No entanto, para efeito do que se quer demonstrar neste artigo, o que mais merece atenção nesse contexto é o novo regimento dado ao governador-geral do Brasil Roque da Costa Barreto, em 1677. ${ }^{25}$ Cabe aqui um questionamento: seriam ${ }^{22}$ J. H. Elliott, La Espana Imperial. 1469-1716, Barcelona, Mondadori, 1998, p. 179-180, apud Francisco Carlos Cardoso Cosentino, op. cit., p. 138.

${ }^{23}$ Antônio Manuel Hespanha, As vésperas do Leviathan, Coimbra, Almedina, 1994, p. 291.

${ }^{24}$ Maria de Fátima Silva Gouvêa, "Conexões imperiais: oficiais régios no Brasil e Angola (c.16801730)", in: Maria Fernanda Bicalho e Vera Lúcia Amaral Ferlini, Modos de governar. Idéias e práticas políticas no império português - séculos XVI a XIX, São Paulo, Alameda, 2005, p. 183.

${ }^{25}$ Regimento do Governador e Capitão-General do Estado do Brasil, passado em 23 de janeiro de 1677, pelo Príncipe D. Pedro, regente de Portugal, publicado em João Alfredo Libânio Guedes, História administrativa do Brasil - Da Restauração a D. João V, Brasília, Fundação Centro de Formação do Servidor Público, 1984, p. 129. Daqui em diante esse documento será referido como Regimento de Roque da Costa Barreto. 
essas medidas o início de um reordenamento da forma de ser da administração, ou a retomada de um modo de governar que encontra suas bases assentadas no período dos Filipes? Talvez uma análise do regimento dado a Roque da Costa Barreto possa ajudar a responder essa questão. Vamos a ela.

Escrito em Lisboa aos vinte e três dias do mês de janeiro de 1677, o regimento dado a Costa Barreto trata-se de uma compilação dos regimentos anteriores. Segundo o próprio príncipe regente, o documento havia sido feito "tendo consideração a não haver no Governo Geral do Estado do Brasil Regimento certo, por onde os Governadores dele hajam de administrar o bom Governo do dito Estado". Logo, o regimento que levava Costa Barreto deveria também servir "para os mais Governadores que lhe sucederem".

Fazendo uma leitura rápida do documento, pode-se perceber que mais uma vez um grande número de seus capítulos faz menção ao envio de informação ao rei. Nesse caso, são 30 capítulos de 61. Já nos primeiros, que, seguindo o modelo filipino, instruem sobre a posse do governador, o modo de governar por escrito aparece. Seguindo a tendência anunciada quando na referência ao regimento de Diogo Mendonça Furtado, o de Costa Barreto também apresenta um maior detalhamento sobre a forma do envio da informação. São várias as menções, ao longo dos capítulos, da necessidade do envio de cópias de documentos via o Conselho Ultramarino, principalmente. Também nele se repetem as instruções sobre a busca pelas minas de salitre que, salvo no de Gaspar de Sousa, constam dos outros dois regimentos dos tempos dos Filipes, isto é, o de Francisco Giraldes e o de Mendonça Furtado.

Seguindo também tendências filipinas, devia Roque da Costa Barreto, bem como os seus sucessores, produzir um livro de governo. Repare-se como o regente da monarquia portuguesa continuava vigilante quanto a ser informado de tudo o que acontecia nos seus domínios ultramarinos.

É possível perceber que o regimento de Roque da Costa Barreto não inova ao dar ênfase na necessidade do governador mandar notícias ao reino. Assim, mais que pelo "início de um reordenamento da forma de ser da administração", como quis Maria de Fátima Gouvêa, a década de 70 do XVII pode ser caracterizada pela reafirmação de um modo de governar assentado na escrita, introduzido no ultramar pelos reis espanhóis - modo de governar que terá o seu auge na década de 90 do mesmo século, quando então governaram o Estado do Brasil Antônio Luís Gonçalves da Câmara Coutinho e João de Lencastre, seu primo. 


\section{Regimentos e cartas: o dia-a-dia da governação}

Cinco foram os regimentos feitos para o governo-geral do Brasil, num período de 129 anos. Como chamou a atenção Francisco Cosentino, somente quatro dos cinco governadores que os receberam exerceram suas funções. $\mathrm{O}$ regimento dado a Roque da Costa Barreto foi o último da série, tendo regulado as administrações posteriores até o século XIX. Mas, afinal, como se dava a governação? Como fazia o governador para cumprir seu regimento e, assim, cumprir com as obrigações a ele incumbidas pelo rei?

Em trabalho já muitas vezes citado, Cosentino, depois de uma análise comparativa dos regimentos, debruçou-se sobre as administrações de cada um dos quatro ministros que de fato exerceram as suas funções. No entanto, podese dizer que, na análise empreendida pelo autor, o governador é o presente mais ausente, ou seja, está em todos os lugares, mas ao mesmo tempo em lugar nenhum. Cosentino percebe, principalmente, a partir do regimento de 1677, o crescimento da importância do governador, mas ainda assim, ao analisar a ação desses homens, eles pouco falam e só recebem ordens. ${ }^{26}$

Como se tentou mostrar, paralelamente ao aumento de importância da figura do governador, houve um crescimento da obrigação de se escrever ao reino. Assim, para uma melhor compreensão do cotidiano da governação, deve-se estar atento para a correspondência produzida pelos governadores.

É chegada a hora de fazer um exercício de olhar para o tempo de outro governador e perceber como carta e regimento foram conjugados de modo a melhor entender como se dava o dia-a-dia da governação. Para tanto, deve-se voltar à epígrafe desse artigo. Nela, dizia o então governador-geral do Brasil, Antônio Luís da Câmara Coutinho, que, conforme regimento, enviava notícias ao reino por carta. Essa parece ter sido a tônica do tempo de Câmara Coutinho no governo-geral do Brasil, isto é: buscar cumprir o regimento, mantendo sempre o rei informado. Muitas foram as cartas escritas pelo governador mas, por ora, algumas questões serão eleitas de modo a demonstrar como tal conjugação pode ser percebida na década de 90 dos seiscentos. Passemos, portanto, a elas.

$* * *$

${ }^{26}$ Idem, p. 204-231. 
Chegado Câmara Coutinho à Bahia, em 1690, o regimento em vigor era o mesmo de 1677. Assim, comparando-o com sua correspondência, pode-se dizer que Câmara Coutinho governou com o regimento em mente e a pena à mão.

Diz o segundo capítulo do regimento que, uma vez aportado na Bahia, devia o governador apresentar a patente passada pelo rei, assim como a carta de herança que desobrigava o antecessor de suas funções. Deveria tomar posse diante das pessoas mais importantes da cidade - bispo, vereadores, ouvidorgeral e provedor da fazenda - e da entrega do governo "se farão os termos que se me hão de neviar [enviar] pelo meu Conselho Ultramarino, para todo o tempo constar, que se procedeu conforme a ordem que sempre se usou em atos semelhantes". 27

Em julho de 1691, na primeira frota que zarpou do porto de Salvador depois de sua chegada, escreveu Câmara Coutinho longa carta para Mendo de Foios Pereira, secretário de Estado, em que dava notícias do estado em que havia encontrado a Bahia, informando o que já havia feito. No final da carta, informava remeter "a V.M. a certidão de como tomei a homenagem nas mãos do Arcebispo desta Cidade". A situação de Câmara Coutinho era um tanto incomum, pois assumia o governo-geral do Estado do Brasil após rápida passagem pela capitania de Pernambuco. Sendo assim, a cerimônia de transferência de poder do rei para o governador, denominada de preito e menagem, teve de ser feita em terras americanas e sem a presença do rei, substituído, nesse caso, pelo arcebispo, então governador do Estado. Nesse sentido, ao informar e remeter os papéis de sua posse, que incluíam as certidões de preito e menagem, cumpria Câmara Coutinho o regimento e legitimava o seu poder diante dos principais da terra.

Questão importante, em se tratando da administração do Estado do Brasil, a defesa mereceu destaque nos regimentos. Assim, a existência ou não de salitre em terras americanas tornou-se neles uma constante.

Já em 1588, Filipe II encomendava a Francisco Giraldes “pela muita necessidade que neste Reino há de salitre para se fazer a pólvora necessária para minha Armada" que, uma vez na Bahia, se informasse acerca de sua existência. Queria o rei saber a quantidade que poderia se tirar em cada ano, sua qualidade e se seria possível enviá-lo ao reino. Ordenava ainda que o governador contratasse pessoas para proceder ao transporte do salitre até Salvador, para então ser embarcado em pipas nos navios. Terminava instruindo o governador

${ }^{27}$ Regimento de Roque da Costa Barreto, op. cit., p. 129. 
que procurasse "todo o mais salitre que souberdes que há em outras partes; entendendo que nisto me fareis particular serviço, e de que receberei muito contentamento". ${ }^{28}$ Ausente do regimento de Gaspar de Sousa, a instrução sobre o salitre reapareceu no de Diogo de Mendonça Furtado, sendo mantida no de Roque da Costa Barreto, posto que até aquela data não havia ainda sido encontrado. Disso tratava o capítulo 29 do regimento de 1677. Dizia então o regente que havia sido informado por Alexandre de Souza, ex-governador-geral do Brasil, da descoberta das minas de salitre, e "para se saber a utilidade delas, e bondades destes, posto que se mandaram fazer todas as diligências até o presente não resolveu efeito algum". Encomendava e ordenava D. Pedro que o governador mandasse

fazer esta experiência pelo polvorista da praça da Bahia, e depois dela feita me informe com o seu parecer do custo que poderá fazer a minha fazenda o quintal deste salitre, posto na Bahia, ou na praça, que mais perto haver das minas, e se haverá pessoas que as tomem por sua conta, e o preço por que se ajusta o quintal do dito salitre na sobredita forma, para que dando-me de tudo conta, resolva este negócio de tanta utilidade para o provimento da pólvora deste Reino, e suas conquistas, pondo logo o cuidado, e diligência para o bom efeito desta fábrica. ${ }^{29}$

A preocupação em se descobrir as minas de salitre era grande e remontava ao período filipino. No entanto, não obstante a suspeita sobre o descobrimento do mineral, chegava-se à última década dos seiscentos sem que este tivesse sido descoberto. É isso que se pode atestar da carta de Câmara Coutinho, escrita em doze de julho de 1692. Nesta, como havia prometido no ano anterior, esclarece o rei sobre o tal descobrimento. Mencionando o nome de dois supostos descobridores (André de Brito e Domingos Soares da Franca), reafirma Câmara Coutinho que "um e outro se não atreveram a fazer esta diligencia porque é muito mais fácil representar a Vossa Magestade por um papel um descobrimento, que conseguil-o com a obra”. Sendo assim, dizia o governador que vendo a importância do negócio, "não aquietei sem primeiro descobrir por todas as partes, donde se presumia haver salitre". ${ }^{30}$

\footnotetext{
${ }^{28}$ Regimento de Francisco Giraldes, op. cit., p. 265.

${ }^{29}$ Regimento de Roque da Costa Barreto, op. cit., p. 138.

30 "Carta para Sua Magestade sobre o descobrimento do salitre" (12/07/1692), in: "Cartas que o Senhor Antonio Luiz Gonçalves da Câmara Coutinho Governador da Capitania deste Estado do Brasil escreveu a Sua Magestade (...)", publicadas nos Documentos Históricos da Biblioteca Nacional, volume 33 - Provisões, Patentes, Alvarás, Cartas (1648-1711), Rio de Janeiro, Typ.Arch. de Hist. Bras., 1936, p. 440.
} 
Prosseguindo no seu dever de informar ao rei, dizia Câmara Coutinho que as minas mais perto eram em Jacobina, que distava sessenta léguas do porto da Cachoeira, podendo-se embarcar para Salvador, que ficava a quatorze léguas por mar. Nessa localidade, informava o governador, havia uma serra que era toda de salitre.

Dando cumprimento ao regimento, informava que seria necessário o envio de pessoas que soubessem separar o salitre da terra, pois só assim seria possível o transporte do mesmo. Nesse sentido, sugeria ainda que se fizesse uma feitoria no local para se cristalizar mineral, posto que desta maneira poderia ser transportado por cavalos. Diferente de André de Brito e Domingos Soares da Franca, Câmara Coutinho enviou ao reino amostras do salitre e da terra para que pudessem ser examinadas por mestres do reino, para que estes julgassem a qualidade e o rendimento do mineral. Por fim, informava o custo do descobrimento e quem de fato havia feito a descoberta: João Martins Pereira.

Perceba-se como mais uma vez Câmara Coutinho parece conjugar muito bem dois dos principais instrumentos da governação portuguesa no ultramar: o regimento e as cartas, principalmente, e, com isso, os interesses do conjunto de atores sociais envolvidos nas questões que compunham e dinamizavam o cotidiano da administração na América portuguesa. Ao se comparar a carta escrita pelo governador com o regimento que regulava suas atividades, poderse-á ver como cumpriu o determinado pelo rei. Inicialmente, averiguou se a descoberta havia de fato se dado. Uma vez constatado que o dito descobrimento não se tratava de uma quimera, e percebendo a importância do salitre, se empenhou em procurá-lo. Uma vez descoberto, procedeu exatamente da maneira instruída pelo rei. Buscou informações sobre a quantidade, o modo de se transportar e, principalmente, remeteu amostras para o reino; ou seja, descobriu o salitre e enviou ao reino seu parecer, incluindo nele o pedido de mercê para José Martins Pereira, homem que de fato procedeu à descoberta do mineral.

Percorrendo a correspondência de Câmara Coutinho, mais exemplos de como carta e regimento foram conjugados de modo a melhor administrar o Estado do Brasil podem ser encontrados. No entanto, os exemplos analisados nessa reflexão apontam não só para a importância do regimento como documento regulador das atividades dos governadores, mas também, e, principalmente, para a importância das cartas no interior da dinâmica da governação portuguesa no ultramar. Como visto, o período de união das coroas foi fundamental 
para a introdução não só em Portugal, mas também no ultramar, de um modo de governar assentado na prática da escrita. Pouco a pouco, os governadores passaram a ser instruídos a dar sempre conta ao rei do que ocorria em terras tão longínquas. Mundo completamente novo, foi através da escrita que a América portuguesa pôde ser melhor conhecida pela monarquia reinante em Portugal, e, dessa forma, conectada ao vasto império luso - império de papel, não se pode nunca esquecer. E, nesse movimento de descoberta e conexão, os governadores-gerais desempenharam papel preponderante. A despeito do alargamento de seus poderes, viviam os governadores presos a cadeias de papel. Autoridade máxima na América, cabia a eles, principalmente, a tarefa de informar ao rei, sugerindo muitas vezes o que fazer. Eram eles os olhos do rei na conquista. Deviam, por isso mesmo, produzir descrições detalhadas acerca da sociedade que gradativamente ia se estabelecendo nos trópicos. E é por tudo isso que cada vez mais a correspondência produzida por estes homens merece atenção, pois o bom governador, além de respeitar as jurisdições, como quis Cosentino, deveria também governar tendo sempre a pena à mão, de forma a conjugar os diversos interesses em jogo, e disso sempre informar ao rei. 